\title{
Effect of Duty Cycle on the Corrosion of Mg PEO Coatings
}

\author{
Nasrollah Eslamzadeh ${ }^{1}$, Reza Ebrahimi-Kahrizsangi ${ }^{1,}$, saeed Karbasi ${ }^{2}$, Arman Zarebidaki $^{3}$, \\ Farhad Gharavi ${ }^{4}$ \\ ${ }^{1}$ Advanced Materials Research Center, Materials Engineering Department, Najafabad \\ Branch, Islamic Azad University, Najafabad, Iran \\ ${ }^{2}$ Department of Biomaterials and Tissue Engineering, School of Advance Technology in Medicine, \\ Isfahan University of Medical Sciences, Isfahan, Iran \\ ${ }^{3}$ Amirkabir University of Technology, Corrosion Engineering and Material Protection Group, Bandar \\ Abbas Campus \\ ${ }^{4}$ Department of Materials Engineering, Sirjan Branch, Islamic Azad University, Sirjan, Iran \\ E-mail: rezaebrahimi@iaun.ac.ir
}

doi: $10.20964 / 2018.07 .43$

Received: 5 December 2017 / Accepted: 4 March 2018 / Published: 5 June 2018

\begin{abstract}
Plasma electrolytic oxidation (PEO) is the method of applying corrosion resistant coatings on $\mathrm{Mg}$ alloys. Duty cycle is one of the effective parameters on PEO processes that can be employed to investigate the effect of duty cycle on the corrosion behavior. In this study, PEO coatings were fabricated in a silicate electrolyte with duty cycles in the range of 20 to $80 \%$. Phase composition and microstructure of the PEO coatings were analyzed by X-ray diffraction (XRD) and scanning electron microscopy (SEM) followed by energy dispersive spectroscopy (EDS). The corrosion behavior of the PEO coatings was evaluated using potentiodynamic polarization in $3.5 \mathrm{wt} . \% \mathrm{NaCl}$ solution. According to SEM and polarization results, a decrease in the duty cycle from $60 \%$ to $20 \%$ was found to result in about $72 \%$ reduction in the growth rate of PEO coatings and improvement of the coatings morphology; finally, 94\% decrease in corrosion current density was observed.
\end{abstract}

Keywords: Mg, Plasma electrolytic oxidation, Oxide coating, Corrosion resistance, Duty cycle

\section{$\underline{\text { FULL TEXT }}$}

(C) 2018 The Authors. Published by ESG (www.electrochemsci.org). This article is an open access article distributed under the terms and conditions of the Creative Commons Attribution license (http://creativecommons.org/licenses/by/4.0/). 